\title{
LETTER
}

\section{Hydroxychloroquine pharmacokinetic in COVID-19 critically ill patients: an observational cohort study}

\author{
Benoit Painvin ${ }^{1 *}$ (D) Pauline Guillot ${ }^{1}$, Marie-Clémence Verdier ${ }^{2,3}$, Arnaud Gacouin ${ }^{1,3}$ and Adel Maamar ${ }^{1,3}$
}

๑ 2020 Springer-Verlag GmbH Germany, part of Springer Nature

\section{Dear Editor,}

The benefit of hydroxychloroquine (HCQ) in the treatment of coronavirus disease (COVID-19) is still under investigation, and randomized control trials worldwide are currently recruiting patients. Data on HCQ pharmacokinetics (PK) exist in lupus patients but are scarce in COVID-19 critically ill patients [1-3]. In our intensive care unit (ICU), patients were started on a 10-day oral course of HCQ $200 \mathrm{mg}$ t.i.d, or $200 \mathrm{mg}$ b.i.d if they had acute kidney injury (AKI) defined as creatinine clearance $<50 \mathrm{ml} / \mathrm{min}$ [4]. Oral loading dose was $400 \mathrm{mg}$, or $200 \mathrm{mg}$ if patients had AKI. We targeted trough blood concentrations between 1 and $2 \mathrm{mg} / \mathrm{L}[4,5]$. HCQ can induce critical side effects such as prolonged QT on electrocardiogram (EKG), severe arrhythmias, and hypoglycemia. This toxicity combined with lack of experience using HCQ led us to measure daily blood trough and peak concentrations over a 12-day period to evaluate PK parameters. Samples were also collected around first hemodialysis (HD) session and in dialysis bath.

We included eight patients with normal renal function, five patients with AKI of whom four required renal replacement therapy and one patient with veno-venous extracorporeal life support (ECLS) (eFig. 2). Median age was 58 (interquartile range 53-70) years, seven (50\%) male, and Sequential Organ Failure Assessment (SOFA) score at admission was 5 (3-7). At day one of treatment, all patients were mechanically ventilated. Median

\footnotetext{
${ }^{*}$ Correspondence: benoit.painvin@chu-rennes.fr

${ }^{1}$ Service de Maladies Infectieuses et Réanimation Médicale, Centre Hospitalier Universitaire de Rennes, Hôpital Pontchaillou, 2 rue Henri le Guilloux, 35033 Rennes Cedex 9, France

Full author information is available at the end of the article
}

albumin level was $27(24-30) \mathrm{g} / \mathrm{L}$, and total bilirubin serum level was $6(4-8.5) \mu \mathrm{mol} / \mathrm{l}$ (eTable 1$)$. We found median HCQ peak concentrations after loading dose of $400 \mathrm{mg}$ and $200 \mathrm{mg}$ were $0.5(0.28-0.62) \mathrm{mg} / \mathrm{L}$ and $0.22(0.2-0.24) \mathrm{mg} / \mathrm{L}$, respectively (eTable 2$)$. Median time to obtain concentration of $1 \mathrm{mg} / \mathrm{L}$ was 4 (3-7) days (Fig. 1), and median duration in therapeutic range was 3.3 days. Toxic levels were noted after day five of treatment (Fig. 1). We found unchanged HCQ concentrations before and after HD sessions and low HCQ concentration in dialysis bath: $0.01 \mathrm{mg} / \mathrm{L}$ and $0.032 \mathrm{mg} / \mathrm{L}$ at halftime and at disconnection of dialysis line, respectively. Finally, three out of 14 patients $(21 \%)$ with blood concentration in therapeutic range had side effects: two with prolonged QT who needed a treatment cessation and one with severe hypoglycemia who required a decreased HCQ dosage.

Our results suggest that prescribing HCQ in COVID19 patients is unsafe for several reasons. Because of drug accumulation and high volume of distribution, toxic threshold was reached by day 5 even in patients with normal renal function. We recorded side effects although patients' blood concentrations were in therapeutic range, therefore making HCQ administration potentially harmful despite correct surveillance parameters. HD had little effect on HCQ concentrations, whereas the patient with ECLS expressed constant low HCQ blood concentration, possibly due to membrane adsorption. To avoid HCQrelated complications in COVID-19 critically ill patients, we suggest monitoring EKG and blood concentration daily. In summary, we believe that for safety reasons, HCQ should not be prescribed outside of randomized controlled trials anymore. 


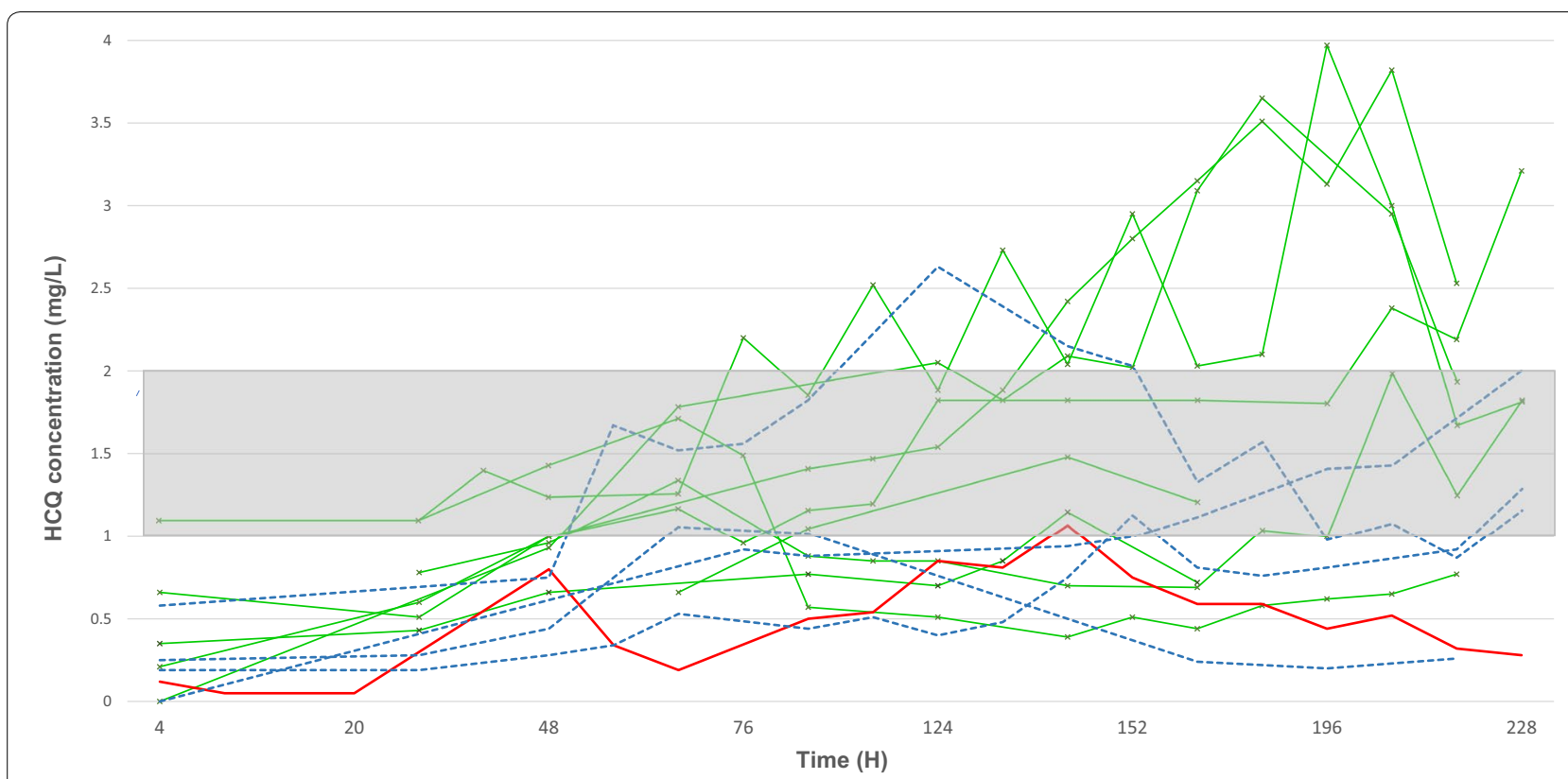

Fig. 1 Hydroxychloroquine pharmacokinetics over a period of ten days in fourteen ICU patients. Red line represents one patient with veno-venous extracorporeal life support (ECLS), green lines depict patients with normal renal function and blue dash curves show patients with acute kidney injury requiring renal replacement therapy. Therapeutic zone is the gray area between $1 \mathrm{mg} / \mathrm{L}$ and $2 \mathrm{mg} / \mathrm{L}$. Overall, $212 \mathrm{HCQ}$ levels were analyzed over the study period. All patients but one (93\%) achieved minimum therapeutic level. After $124 \mathrm{~h}$, patients are more at risk of having residual and peak levels in the toxic zone, i.e., $2 \mathrm{mg} / \mathrm{L}$. The patient with veno-venous ECLS remains under the lower therapeutic level of $1 \mathrm{mg} / \mathrm{L}$

The local ethics committee approved the study (Institutional Review Board of the Rennes University Hospital, accord no 20.38). All patients signed written informed consent.

\section{Electronic supplementary material}

The online version of this article (https://doi.org/10.1007/s00134-020-06142-y) contains supplementary material, which is available to authorized users.

\section{Author details}

1 Service de Maladies Infectieuses et Réanimation Médicale, Centre Hospitalier Universitaire de Rennes, Hôpital Pontchaillou, 2 rue Henri le Guilloux, 35033 Rennes Cedex 9, France. ${ }^{2}$ Laboratoire de Pharmacologie Biologique, Centre Hospitalier Universitaire Pontchaillou, 2 rue Henri le Guilloux,

35033 Rennes Cedex 9, France. ${ }^{3}$ Faculté de Médecine, Université de Rennes 1, Unité INSERM CIC 1414, IFR 140, Rennes, France.

\section{Authors' contribution}

BP conceptualized the study and participated in its design, data acquisition and analysis, literature research, and manuscript drafting. PG participated in data acquisition and analysis, literature research, and manuscript drafting. MCV participated in data acquisition and analysis and manuscript drafting. AG participated in data acquisition and analysis, revising of the article for important intellectual content, and manuscript drafting. AM participated in data acquisition and analysis, revising of the article for important intellectual content, and manuscript drafting. All authors read and approved the final manuscript.

\section{Compliance with ethical standards}

\section{Conflicts of interest}

On behalf of all authors, the corresponding author states that there are no conflicts of interest.

\section{Publisher's Note}

Springer Nature remains neutral with regard to jurisdictional claims in published maps and institutional affiliations.

\section{Accepted: 26 May 2020}

Published online: 8 June 2020

\section{References}

1. Al-Rawi H, Meggitt SJ, Williams FM, Wahie S (2018) Steady-state pharmacokinetics of hydroxychloroquine in patients with cutaneous lupus erythematosus. Lupus 27:847-852. https://doi.org/10.1177/0961203317 727601

2. Perinel S, Launay M, Botelho-Nevers É et al (2020) Towards optimization of hydroxychloroquine dosing in intensive care unit COVID-19 patients. Clin Infect Dis Off Publ Infect Dis Soc Am. https://doi.org/10.1093/cid/ ciaa394

3. Garcia-Cremades M, Solans BP, Hughes E et al (2020) Optimizing hydroxychloroquine dosing for patients with COVID-19: an integrative modeling approach for effective drug repurposing. Clin Pharmacol Ther. https://doi. org/10.1002/cpt.1856

4. Durcan L, Clarke WA, Magder LS, Petri M (2015) Hydroxychloroquine blood levels in systemic lupus erythematosus: clarifying dosing controversies and improving adherence. J Rheumatol 42:2092-2097. https://doi. org/10.3899/jrheum.150379

5. Yao X, Ye F, Zhang M et al (2020) In vitro antiviral activity and projection of optimized dosing design of hydroxychloroquine for the treatment of severe acute respiratory syndrome coronavirus 2 (SARS-CoV-2). Clin Infect Dis Off Publ Infect Dis Soc Am. https://doi.org/10.1093/cid/ciaa237 